Volume 5 Mei, 2022 (51-60)

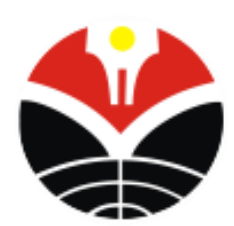

JTIKOR (Jurnal Terapan Ilmu Keolahragaan)

http://ejournal.upi.edu/index.php/JTIKOR

doi: $\underline{10.17509 / \text { itikor.v5i1.24415 }}$

\title{
Bagaimana Motivasi Olahraga Mahasiswa di Papua?
}

\author{
Miftah Fariz Prima Putra ${ }^{1 \bowtie}$ \\ ${ }^{1} 1 \mathrm{mu}$ Keolahragaan, Fakultas Ilmu Keolahragaan, Universitas Cenderawasih, Provinsi Papua, \\ Indonesia
}

\section{Info Artikel}

Kata Kunci:

Motivasi olahraga; intrinsik, mahasiswa; Papua

Keywords:

sport motivation, intrinsic, college student, Papua

Alamat korespondensi: J1. Kambolker Perumnas III, Yabansai, Heram, Kota

Jayapura, Papua 99224

E-mail: mifpputra@gmail.com

\begin{abstract}
Abstrak
Penelitian ini memiliki tujuan untuk mengungkap bagaimana motivasi olahraga mahasiswa yang ada di Papua. Jenis penelitian yang digunakan adalah survai dengan partisipan mahasiswa sebesar 88 orang (41 laki-laki dan 47 perempuan) dan rata-rata umur responden adalah 20,65 (SD: 2,4). The Sport Motivation Scale digunakan untuk mengambil data penelitian. Analisis deskriptif seperti nilai rata-rata, nilai terendah dan tertinggi, serta standar deviasi akan digunakan dalam studi ini. Hasil penelitian menemukan dimensi motivasi olahraga mahasiswa di Papua yang paling tinggi adalah intrinsic motivation-to experience stimulation $(22,99)$, sedangkan yang paling rendah adalah amotivation $(13,70)$. Motivasi olahraga internal lebih mendominasi dalam diri mahasiswa di Papua dibanding dengan eksternal dan dismotivasi.
\end{abstract}

\section{Abstract}

The purpose of this study was to reveal the sport motivation on the student sports in Papua. The survey research will be used in this study by involving 88 student as the sample (41 male and 47 female) and the average age of the respondents was 20,65 (SD: 2.4). Data was collected using The Sport Motivation Scale. Descriptive analysis such as mean value, lowest and highest value, and standard deviation will be used in this study. The results found the highest dimension of student sports motivation in Papua was intrinsic motivation-to experience stimulation (22.99), while the lowest was amotivation (13.70). Internal sports motivation is more dominant in students in Papua compared to external and motivated. 


\section{PENDAHULUAN}

Terdapat bukti yang menunjukkan bahwa olahraga secara teratur dan dengan porsi yang tepat maka akan meningkatkan kesehatan tubuh dan mental. Hal ini sejalan dengan yang diungkapkan oleh Pelletier et al., (2013) bahwa rutin berolahraga akan memberikan manfaat postif seperti meningkatnya kebugaran, selfestem dan meminimalisir kemungkinan mengalami sakit. Keuntungan inilah yang kerap menjadi sebab orang melakukan olahraga (Kilpatrick, Hebert \& Bartholomew, 2005). Blegur \& Mae (2018) menyebutkan keterlibatan individu dalam suatu aktifitas fisik seperti olahraga didasarkan adanya suatu dorongan, baik yang bersumber dalam dirinya maupun dari luar. Dorongan atau pengerak inilah yang kerap disebut dengan motivasi (Maksum, 2011; Dimyati, 2018). Meskipun acapkali didefiniskan secara berbeda (Komarudin, 2015: 23) namun secara umum, motivasi dapat dipahami sebagai sumber penggerak atau pendorong yang ada dalam diri seseorang untuk melakukan sesuatu.

Berbagai literatur psikologi olahraga menempatkan objek kajian motivasi sebagai bagian yang penting (Dimyati, 2019). Bahkan, dalam konteks olahraga prestasi, banyaknya atlet gagal berprestasi maksimal disebabkan karena rendahnya motivasi olahraga yang dimiliki (Ginting, Sitepu \& Jubaedi, 2018). Itu sebabnya, Pelletier et al., (1995) menyebutkan kalau motivasi merupakan inti dari berbagai masalah olahraga yang menarik dikaji. Tidak jauh berbeda, Tangkudung \& Mylsidayu (2017) menyatakan bahwa dalam psikologi olahraga, motivasi, menjadi menarik karena merupakan aspek yang paling terkendali. Dengan demikian tidak berlebihan jika ada yang menyebut hampir $25-30 \%$ kajian psikologi olahraga membahas tentang motivasi (Dimyati, 2018; Dimyati, 2019).

Meskipun menjadi variabel yang menarik dikaji, namun bukan berarti motivasi olahraga adalah konstruk yang sederhana. Pelletier et al., (2013) menyatakan bahwa fenomena motivasi berolahraga merupakan fenomena yang kompleks. Menjadi kompleks karena faktor yang melatar belakangi melakukan olahraga tidak beralur tunggal namun multi faktor. Tangkudung \& Mylsidayu (2017) serta Mylsidayu (2018) menjelaskan bahwa motivasi berolahraga antara individu yang satu dengan lainnya berbeda-beda yang disebabkan karena adanya perbedaan kebutuhan dan kepentingan.

Beberapa literatur dan penelitian sudah mengidentifikasi apa saja motivasi orang melakukan olahraga. Kilpatrick, Hebert \& Bartholomew (2005) dalam penelitiannya pada mahasiswa menemukan bahwa motivasi tertinggi berolahraga adalah karena kompetisi, pertemanan, kesenangan dan adanya tantangan. Gould \& Petlichkoff (dalam Maksum, 2011) menyebutkan motivasi orang melakukan olahraga antara lain untuk memperbaiki keterampilan, mendapatkan kesenagan, mendapatkan teman, memperoleh pengalaman yang menantang, mendapatkan kesuksesan, dan kebugaran. Abdulaziz, Dharmawan \& Putri (2010) menemukan masyarakat berolahraga karena termotivasi faktor fisiologis (kebugaran), kebutuhan rasa aman, kebutuhan sosial dan kebutuhan penghargaan.

Tangkudung \& Mylsidayu (2017) menyebutkan terdapat sepuluh motivasi individu berpartisipasi dalam olahraga antara lain: (1) untuk mengembangkan keterampilan dan kemampuan, (2) untuk berhubungan dan mencari teman, (3) untuk mencapai sukses dan mendapat pengakuan, (4) untuk memelihara kesehatan badan, (5) untuk menyalurkan energi, (6) untuk mendapatkan pengalaman penuh tantangan dan menggembirakan, (7) untuk dapat bersenang-senang dan mendapat kegembiraan, (8) untuk melepaskan ketegangan psikis, misalnya untuk mengatasi lelah dan jenuh dengan rutinitas belajar di sekolah, sehingga ikut ekstrakurikuler sepakbola, (9) untuk kepentingan kebanggaan kelompok, dan (10) untuk kebutuhan praktis sesuai pekerjaan, misalnya olahraga bela diri/menembak yang diikuti oleh Satpam.

Dalam kaitanya dengan motivasi olahraga, Maksum (2011) menyebutkan bahwa partisipasi seseorang dalam olahraga mencerminkan minat dan apresiasinya terhadap kegiatan olahraga. Pertanyaannya kemudian, 
bagaimana partisipasi masyarakat dalam berolahraga? Tahun 2003, BPS menyebutkan bahwa Provinsi yang paling tinggi skornya adalah Banten (42,71\%), DKI (40,3\%) dan Yogyakarta (32,9\%). Sebaliknya, Provinsi yang tingkat partisipasi masyarakatnya paling rendah adalah Sulawesi Selatan (19,9\%), Lampung $(20,2 \%)$, dan Papua $(20,5)$. Dari data tersebut tampak bahwa Provinsi Papua berada diurutan rendah (Maksum, 2011). Namun begitu, survai yang dilakukan oleh BPS adalah tahun 2003 dan bukaan saat ini. Dengan fakta tersebut maka sangat bisa jadi kondisi di masyarakat Papua sudah berubah, yaitu dapat berubah lebih tinggi motivasi olahraganya yang salah satu faktornya adalah karena adanya rencana menggelar Pekan Olahraga Nasional (PON) ke-XX di Papua, atau bahkan sebaliknya. Dari kajian yang dilakukan oleh BPS di atas serta adanya rencana PON di Papua maka peneliti menilai mengkaji motivasi olahraga masyarakat Papua (terutama mahasiswa) menjadi menarik dilakukan agar didapat bukti empirik bagaimana kondisi terbaru motivasi olahraganya. Pada dasarnya, motivasi olahraga penting dimiliki tidak hanya oleh mahasiswa, namun masyarakat secara umum (dewasa dan anak-anak), karena atas dasar inilah orang melakukan olahraga sehingga badan akan menjadi lebih bugar dan kemungkinan terkena penyakit dapat diminimalisir (Pelletier et al., 2013).

Untuk memahami lebih komprehensif ihwal studi tentang motivasi olahraga, peneliti melakukan pencarian dakumen ilmiah hasil riset di Garba Rujukan Digital (http://garuda.ristekbrin.go.id/) dengan kata kunci "motivasi olahraga" dan ditemukan 127 dokumen. Setelah dianalisis lebih lanjut ternyata hanya 15 artikel yang berkaitan dengan motivasi dalam konteks olahraga. Sebagain besar lainnya didominasi oleh motivasi belajar, berprestasi dan lainnya.

Dari 15 artikel yang didapat, setelah dilakukan analisis lebih dalam ditemukan hanya terdapat empat artikel yang membahas secara spesifik tantang motivasi olahraga dan mengunakan instrumen motivasi olahraga (lihat: Santoso, 2015; Asnaldi, Zulman \& Madri,
2018; Sujari, Shomad \& Santoso, 2018; Blegur \& Mae, 2018). Keempat penelitian tersebut sampelnya bukanlah masyarakat atau mahasiswa yang ada di Provinsi Papua. Itu artinya, kajian tentang motivasi olahraga dengan menggunakan instrumen yang umum dipakai secara internasional masih minim dilakukan di Indonesia, apalagi dengan subjek mahasiswa di Papua.

Atas argumentasi di atas, peneliti berpandangan bahwa penting untuk melakukan riset tentang motivasi olahraga pada mahasiswa agar dapat diketahui bagaimana motivasi olahraga masyarakat-terutama pada mahasiswa-di Papua pada saat ini. Selain itu, Allen (2003) menyebutkan bahwa teori-teori motivasi terbaru didominasi dan dikembangkan dari riset dengan subyek usia remaja atau anak muda. Dengan demikian studi ini dilakukan dengan tujuan untuk mengungkap bagaimana motivasi olahraga mahasiswa yang ada di Papua.

\section{METODE}

\section{Metode dan Desain}

Jenis penelitian yang digunakan dalam studi ini adalah survai. Menurut Fraenkel, Wallen \& Hyun (2012: 392) "The major purpose of surveys is to describe the characteristics of a population". Hal yang sama diungkapkan oleh Ary, Jacobs, Sorensen \& Razavieh (2010) bahwa penelitian survai dilakukan karena peneliti ingin mendapatkan informasi berkaitan dengan karakteristik dari populasi yang dipelajari. Pertanyannya kemudian, karakteristik seperti apa yang hendak dipelajari dalam studi ini? Motivasi olahraga yang dimiliki oleh mahasiswa di Papua adalah karakteristik yang akan diungkap dalam riset tersebut. Dengan mengacu pada pendapat di atas maka penelitian tersebut tidak dimaksudkan untuk menguji hipotesis namun diarahkan untuk memahami dan mengungkap dimensi motivasi olahraga yang secara garis besar terbagi menjadi tiga, yaitu intrinsik, ekstrinsik dan dismotivasi. 


\section{Partisipan}

Sampel penelitian ini adalah mahasiswa yang ada di Jayapura, Papua. Teknik pengambilan sampel dilakukan dengan accidental sampling. Itu artinya, enumertor akan mengambil sampel penelitian sesuai yang ditemui ketika berada di lapangan. Kriteria sampel yang diambil adalah mahasiswa di Papua yang statusnya aktif. Melalui Teknik tersebut didapat 88 mahasiswa (41 laki-laki dan 47 perempuan) dengan rata-rata umur partisipan adalah 20,65 tahun dengan SD 2,4

\section{Instrumen}

Instrumen penelitian mengadaptasi dari Sport Motivation Scale (SMS) yang dikembangkan oleh Pelletier et al., (1995). Alat ukur tersebut memiliki reliabilitas yang bergerak antara $0,58-$ 0.84 dengan jumlah item sebanyak 28 pernyataan yang memiliki rentang jawaban secara kontinitas dari sangat tidak sesuai (1) hingga sangat sesuai (7). Secara garis besar SMS terbagi menajadi 3 subskala seperti yang ada di tabel.

Tabel 1. Subskla motivasi olahraga

\begin{tabular}{lll}
\hline Subscale & & \\
\hline $\begin{array}{l}\text { Intrinsic } \\
\text { Motivation }\end{array}$ & $\begin{array}{l}\text { Extrinsic } \\
\text { Motivation }\end{array}$ & Amotivation \\
(IM) & $(\mathrm{EM})$ & \\
\hline IM-to know & EM- & Amotivation \\
& $\begin{array}{l}\text { identified } \\
\text { regulation }\end{array}$ & \\
IM-to & $\begin{array}{l}\text { EM- } \\
\text { accomplish }\end{array}$ & $\begin{array}{l}\text { introjected } \\
\text { regulation }\end{array}$ \\
IM-to & $\begin{array}{l}\text { EM- } \\
\text { experience }\end{array}$ & external \\
stimulation & regulation & \\
\hline
\end{tabular}

\section{Prosedur}

Penelitian ini diawali dengan melakukan penyesuaian Bahasa atau penerjemahan instrumen yang digunakan (hasil adaptasi dapat dilihat pada lampiran). Dalam proses tersebut peneliti dibantu oleh expert bahasa yang sedang menyelesaikan studi di salah satu kampus di Australia. Berikutnya, peneliti memberikan pelatihan pada mahasiswa olahraga tentang cara melakukan pengambilan data di lapangan. Mahasiswa yang dilibatkan adalah mahasiswa yang sedang menempuh mata kuliah psikologi olahraga yaitu yang berada pada semester ke tiga. Hal ini dilakukan karena agar mahasiswa yang dilibatkan sudah memiliki pengetahuan yang baik berkaitan dengan konsep motivasi olahraga dan cara pengambilan datanya. Tahap berikutnya, yaitu meminta izin pada kampus yang ada di Jayapura, Papua bahwa akan dilakukan pengambilan data penelitian tentang motivasi olahraga pada mahasiswa. Tahap selanjutnya adalah mengadministrasikan instrument yang sudah diisi untuk kemudian dilakukan analisis hasilnya

\section{Analisis Data}

Teknik analisis data yang digunakan adalah analisis deskriptif, seperti nilai rata-rata, nilai terendah dan tertinggi, serta standar deviasi. Selain itu, data yang diperoleh juga akan ditampilkan dengan menggunakan chart agar dapat diketahui dan dibaca dengan lebih mudah tentang gambaran motivasi olahraga yang dmiliki mahasiswa di Papua Semua analisis tersebut akan dibantu dengan program SPSS v.26.

\section{HASIL}

Deskripsi hasil penelitian tentang motivasi olahraga mahasiswa di Provinsi Papua tersaji seperti table 1 di bawah ini: 
Tabel 2. Deskripsi nilai motivasi olahraga

\begin{tabular}{|c|c|c|c|c|c|c|c|}
\hline & \multicolumn{7}{|c|}{ Dimensi Motivasi Olahraga } \\
\hline & \multicolumn{3}{|l|}{ Intrinsic } & \multicolumn{3}{|l|}{ Extrinsic } & \multirow{2}{*}{$\begin{array}{l}\text { Amotivation } \\
\text { AMO }\end{array}$} \\
\hline & IM-TK & IM-TA & IM-TES & EM-IDR & EM-INR & EM-ER & \\
\hline Min & 6 & 5 & 6 & 7 & 5 & 4 & 4 \\
\hline $\operatorname{Max}$ & 28 & 28 & 28 & 28 & 28 & 28 & 27 \\
\hline $\mathrm{SD}$ & 4.59 & 5.12 & 4.70 & 5.48 & 5.13 & 5.74 & 5.36 \\
\hline Mean & 21.25 & 20.14 & 22.99 & 20.14 & 21.01 & 13.91 & 13.70 \\
\hline Total & 1870 & 1772 & 2023 & 1772 & 1849 & 1224 & 1206 \\
\hline
\end{tabular}

Sumber: Data primer

Keterangan: IM-TK: Intrinsic motivation-to know, IM-TA: Intrinsic motivation-to accomplish, IM-TES: Intrinsic motivation-to experience stimulation, EM-IDR: Extrinsic motivation-identified regulation, EM-INR: Extrinsic motivation-introjected regulation, EM-ER: Extrinsic motivation-external regulation, AMO: Amotivation

Jawaban responden dengan nilai terkecil (minimal) dari tujuh dimensi motivasi olahraga terdapat pada dimensi extrinsic motivationexternal regulation (4) dan amotivation (4), sedangkan nilai terbesar (maksimal) adalah extrinsic motivation-identified regulation (7). Untuk nilai total setiap dimensi, hanya amotivation (27) yang memiliki nilai lebih kecil dibanding lainnya yaitu 28. Secara keseluruhan, standar deviasi ada pada rentang 4,59 hingga 5,74 . Nilai rata-rata setiap dimensi motivasi olahraga yang paling tinggi adalah Intrinsic motivation-to experience stimulation $(22,14)$ sedangkan yang paling rendah adalah amotivation $(13,7)$. Skor total Intrinsic motivation-to experience stimulation adalah yang paling tinggi (2023), sedangkan Intrinsic motivation-to accomplish adalah yang paling kecil (1772). Untuk gambaran rata-rata setiap dimensi motivasi olahraga tersaji pada gambar 1 berikut ini.

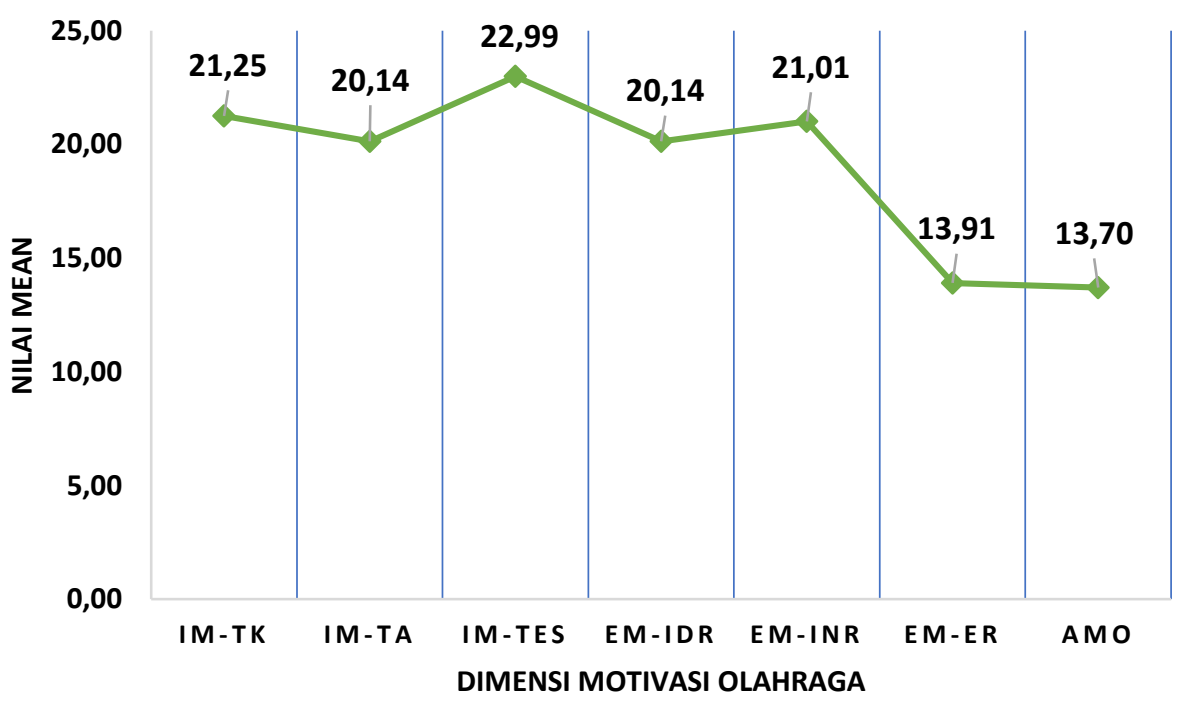

Gambar 1

Gambaran dimensi motivasi mahasiswa 
Tujuh dimensi motivasi olahraga mahasiswa di Papua telah diungkap dan tersaji di atas. Dari gambar tersebut tampak bahwa motivasi olahraga yang bersumber dari dalam diri (internal) cenderung memiliki nilai lebih tinggi dibanding dengan dimensi lainnya.

\section{PEMBAHASAN}

Hasil penelitian menunjukkan bahwa motivasi intriksik memiliki skor paling tinggi bila disbanding dengan dimensi lainnya. Ryan \& Deci (2000) menyatakan bahwa ketika seseorang termotivasi secara intrinsik, orang tersebut akan bergerak dan bertindak untuk bersenang-senang atau bahkan tertantang dalam melakukannya, dan bukan karena faktor eksternal seperti tekanan atau imbalan. Dengan demikian motivasi intrinsik dapat dipahami sebagai adanya dorongan dalam melakukan aktifitas fisik atau kegiatan olahraga yang disebabkan karena adanya rasa senang dan bangga dalam diri orang tersebut. Hal ini sesuai dengan apa yang dikatakan oleh Gillet Vallerand, Amoura, \& Baldes (2010) bahwa motivasi intrinsik mengacu pada tindakan atau aktifitas yang dilakukan untuk kesenangan dan kepuasan. Dalam konteks atlet, Vallerand \& Losier (1999) menyatakan bahwa motivasi instrinsik merupakan adanya pengerak dalam diri yang disebabkan oleh rasa senang dan bangga ketika melakukannya. Hasil penelitian ini menujukkan bahwa dimensi intrinsic motivation-to experience stimulation memiliki nilai yang peling tinggi dibanding dengan dimensi motivasi olahraga lainnya.

\section{Intrinsic motivation-to experience stimulation}

Dari hasil penelitian, dimensi Intrinsic motivation-to experience stimulation adalah dimensi yang nilai rata-ratanya paling tinggi dibanding dengan enam dimensi lainnya. Secara sederhana intrinsic motivation-to experience stimulation dapat dipahami sebagai suatu kondisi dimana seseorang mengalami perasaan senang pada saat berada dan berpartisipasi dalam kegiatan olahraga (Pelletier et al., 1995). Rasa senang, bangga dan aspek positif lainnya yang diperoleh saat berpartisipasi dalam olahraga merupakan stimulus yang diakibatkan oleh pengalaman yang ada. Dengan demikian, hasil penelitian yang menempatkan dimensi tersebut berada pada posisi paling tinggi mengindikasikan bahwa alasan mahasiswa di Papua melakukan olahraga lebih didominasi oleh pengalaman yang mengakibatkan rasa senang.

Menurut Utami \& Kriswanto (2019) munculnya rasa kegembiraan saat berolahraga membuat seseorang dapat mengekspresikan diri sehingga dapat tercapainya kebahagiaan atau yang biasa disebut dengan psychological wellbeing. Zulkarnaen (2010) menyebutkan jika aktivitas yang dilakukan (olahraga) memberikan manfaat yang nyata, maka partisipasi seseorang dalam olahraga tersebut akan bertahan lama dengan frekuensi yang lebih banyak pula.

\section{Intrinsic motivation-to know}

Dimensi motivasi olahraga tertinggi yang kedua adalah intrinsic motivation-to know. Pelletier et al., (1995: 36) menyebutkan bahwa dimensi tersebut berkaitan dengan timbulnya rasa senang dalam diri seseorang ketika melakukan aktifitas olahraga yang disebabkan karena mendapatkan pengalaman, pengetahun atau keterampilan baru. Mengacu pada pemahaman tersebut maka dapat dikatakan bahwa terdapat mahasiswa di Papua yang melakukan olahraga karena meraka merasa senang mendapatkan pengetahuan dan ketarampilan baru.

Hasil penelitian yang dilakukan oleh Abidin \& Priambodo (2017) menyebutkan bahwa motivasi mahasiswa mengikuti kegiatan olahraga yang paling tinggi adalah untuk mendapatkan ketarampilan (skill) baru. Dengan keterampilan baru yang diperoleh ini maka mahasiswa akan merasa senang dalam berolahraga. Oleh akarena itu, tidak mengherankan jika alasan ini cukup dominan atau tinggi dalam motivasi berolahraga.

\section{Intrinsic motivation-to accomplish}

Dimensi motivasi intrinsik berikutnya adalah Intrinsic motivation-to accomplish. Pelletier et al., (1995) menyebutkan bahwa dimensi ini berkaitan dengan adanya rasa senang dan bangga dalam diri seseorang saat berolahraga 
karena orang tersebut mendapatkan apa yang ditargetkan. Pencapaian tersebut erat dengan pretasi yang diharapkan sehingga timbullah rasa puas. Dengan dasar penjelasan tersebut maka dapat dipahami bahwa terdapat mahasiswa di Papua yang melakukan olahraga karena adanya rasa senang saat berolahraga terutama ketika apa yang ditargetkan dapat tercapai.

Dimensi berikutnya tentang motivasi olahraga yang disebutkan oleh Pelletier et al., (1995) adalah ekstrinsik. Blegur \& Mae (2018) menjelaskan bahwa motivasi ekstrinsik lebih berfokus pada unsur-unsur ekstrinsik ketika individu berpartisipasi dalam kegiatan olahraga. Vallerand \& Losier (1999) mengatakan motivasi eksternal adalah adanya sumber pengerak dari luar seperti materi, sosial dan untuk menghindari hukuman. Secara sederhana motivasi eksternal dapat dihamai sebagai adanya sumber dorongan dari luar (eksternal) untuk melakukan aktifitas olahraga.

Pada awalnya, dimensi motivasi ekstrinsik dianggap sebagai suatu yang tidak dapat diatur dan hanya bersumber dari eksternal seperti adanya penghargaan, namun baru-baru ini terdapat bukti bahwa terdapat beberapa jenis motivasi eksternal yang dapat diatur dan oleh pelletier dkk hal ini dibagi menjadi tiga yaitu extrinsic motivation-identified regulation, extrinsic motivation-introjected regulation, extrinsic motivation-external regulation. Dari ketiga jenis dimensi tersebut, hasil penelitian ini menemukan bahwa extrinsic motivationintrojected regulation memiliki nilai rata-rata yang paling tinggi.

\section{Extrinsic motivation-introjected regulation}

Dimensi extrinsic motivation-introjected regulation dapat dipahami bahwa seseorang berpartisipasi dalam kegiatan olahraga karena adanya suatu tekanan seperti rasa malu ketika tidak ikut berpartisipasi (Pelletier et al., 1995). Perilaku yang bersifat introjected regulation ditunjukkan dengan adanya proses internalisasi alasan-alasan untuk melakukan sesuatu dan melakukan rasionalisasi atas apa yang dilakukan meskipun itu bukan bersumber dari dirinya (Maksum, 2011)
Atas dasar penjelasan tersebut maka tingginya nilai rata-rata pada dimensi ini menunjukkan bahwa mahasiswa di Papua melakukan aktifitas olahraga karena adanya tekanan psikis seperti merasa malu kalau tidak ikut serta dalam kegiatan olahraga. Itu artinya, keterlibatan mereka dalam aktifitas olahraga bukan disebabkan oleh dorongan dari dalam, namun karena adanya faktor luar atau eksternal. Munculnya motivasi tersebut dalam konteks mahasiswa sangat bisa jadi karena antara mahasiswa satu dengan yang lain memiliki hubungan yang cukup erat dalam kelompoknya, sehingga ketika mereka tidak ikut serta dalam apa yang dilakukan oleh kelompoknya maka itu akan membuat yang bersangkutan merasa malu. Selain itu, adanya mata kuliah olahraga juga dapat menjadi alasan kenapa mahasiswa merasa malu kalua tidak ikut berolahraga.

\section{Extrinsic motivation-identified regulation}

Dimensi motivasi olahraga yang nilainya urutan kedua adalah extrinsic motivation-identified regulation. Dimensi tersebut menunjukkan bahwa orang yang berpartisipasi dalam kegiatan olahraga memiliki pandangan bahwa olahraga itu penting untuk dirinya dalam mencapai sesuatu yang diinginkan (missal: kebugaran, keterampilan, kemenangan) tanpa adanya alternatif lainnya untuk mengapai tujuannya tersebut (Pelletier et al., 1995). Dari penjelasan tersebut dapat dipahami bahwa terdapat mahasiswa di Papua yang melakukan aktifitas olahraga karena mereka mempersepsikan bahwa olahraga itu penting untuk dirinya.

$$
\text { Dalam penelitian Abdulaziz, }
$$

Dharmawan \& Putri (2010) disebutkan bahwa mendapatkan manfaat secara fisiologis (kebugaran) adalah alas an tertinggi orang melakukan olahraga. Hal ini dapat dimaklumi karena dengan berkembangnya informasi dan teknologi maka orang akan sadar betapa pentingnya olahraga bagi Kesehatan tubuh. Dengan melukangkan waktu tiga kali dalam seminggu dan tiga puluh menit dalam sekali berolahraga maka manfaat secara fisiologis dapat diperoleh. 
Extrinsic motivation-external regulation

Dalam penelitian ini ditemukan dimensi motivasi eksternal yang nilainya paling rendah adalah extrinsic motivation-external regulation. Pelletier et al., (1995) mengatakan bahwa sesuai dengan namanya maka pada dimensi tersebut orang melakukan aktifitas olahraga karena adanya faktor eksternal seperti imbalan materi, pujian dan bahkan adanya paksaan dari orang lain. Hal senada diungkapkan oleh Maksum (2011) bahwa suatu perilaku didorong oleh external regulation manakala perilaku tersebut diarahkan oleh faktor seperti hadiah atau paksaan. Penjelasan yang lebih sederhana dinyatakan oleh Komarudin (2015) bahwa external regulation memiliki maksud untuk memuaskan tuntutan yang bersifat eksternal.

Atas penjelasan tersebut maka dapat dikatakan bahwa terdapat mahasiswa di Papua yang melakukan olahraga karena adanya imbalan dan/atau paksaan yang dialaminya. Paksaan yang dialami bisa bersumber dari teman kuliah di kampus atau bahkan dari adanya mata kuliah olahraga sehingga hal itu mengharuskan mahasiswa tersebut melakukan aktifitas olahraga. Meskipun hasil penelitian ini telah menemukan bahwa motivasi ekstrinsik memiliki nilai rata-rata yang cukup, namun itu bukan berarti bersifat mutlak. Motivasi olahraga merupakan kondisi psikis yang bersifat kontinum, yaitu dapat berubah seiring waktu dan sebab. Jadi, seseorang yang saat ini memiliki motivasi ekstrinsik sangat bisa jadi akan berubah instrinsik atau sebaliknya.

\section{Amotivation}

Dimensi motivasi olahraga yang nilainya paling rendah dibanding yang lain adalah amotivation. Pelletier et al., (1995) menyebutkan bahwa dimensi amotivation menunjukkan bahwa individu melihat bahwa tidak adanya hubungan antara melakukan aktifitas olahraga dengan hasil yang didapat. Whitehead (dalam Maksum, 2011) menempatkan amotivation sebagai tangga tersendiri dalam konstruk motivasi olahraga. Dengan kerangka pemikiran yang demikian, terbuka kemungkinan seseorang yang tidak memiliki motivasi (amotivasi) dapat berubah memiliki motivasi eksternal dan kemudian internal.

Adanya mahasiswa yang memiliki amotivasi menunjukkan bahwa mahasiswa tersebut tidak termotivasi, baik yang bersumber dalam dirinya (internal) maupun yang bersumber dari luar (eksternal). Meskipun hasil penelitian menujukkan nilai dimensi tersebut yang paling rendah dibanding enam dimensi lainnya, namun faktanya tetap ada mahasiswa yang tidak tertarik dalam melakukan olahraga. Hal ini sejalan dengan laporan BPS tahun 2003 yang menyebutkan bahwa masyarakat di Provinsi Papua motivasi berolahraganya rendah.

Pertanyaannya kemudian, bagaimana cara meningkatkan motivasi olahraga mahasiswa? Beberapa strategi dapat dilakukan. Misalnya, memberikan pujian atau penguatan saat mahasiswa menunjukkan semangat berolahraga; merubah fokus atau target yang diberikan dari menang-kalah menjadi ukuranukuran performa seperti meningkatnya kecepatan, kekuatan, kebugaran dan aspek performa lainnya; melakukan rekayasa lingkungan-sosial dengan menciptakan situasi menyenangkan ketika berolahraga. Sebagai contoh, memberikan permainan kecil untuk menganti pemanasan (statis atau dinamis) yang dilakukan sebelum masuk pada materi inti olahraga (Maksum, 2011; Komarudin, 2015; Mylsidayu, 2018).

Meski terdapat macam-macam strategi dalam meningkatkan motivasi namun hal pertama yang perlu diketengahkan menurut Maksum (2011) adalah pahami faktor pribadi individu dan situasi yang ada. Jangan mengambil Langkah apapun sebelum memahami apa yang menyebabkan individu kurang termotivasi, apakah itu karena faktor diri individua tau lingkungan. Andaikata factor yang menyababkan adalah dari individu maka perlu adanya pendekatan pribadi, tetapi jika faktor penyebabnya adalah lingkungan maka perlu memodifikasi lingkungan yang lebih menarik. 


\section{KESIMPULAN}

Berdasarkan hasil dan pembahasan di atas maka simpulan penelitian ini adalah dimensi motivasi olahraga mahasiswa di Papua yang paling tinggi adalah intrinsic motivation-to experience stimulation $(22,99)$, sedangkan yang paling rendah adalah amotivation $(13,70)$. Hal ini bermakna bahwa motivasi olahraga internal lebih mendominasi dalam diri mahasiswa di Papua dibanding dengan eksternal dan dismotivasi (amotivation). Penelitian kedepan hendaknya dilakukan dengan subjek lebih luas dan dengan memperdalam analisis seperti mengaitkan dengan gender, usia, asal daerah atau suku dan bidang studi mahasiswa

\section{REFERENSI}

Abdulaziz, M., Dharmawan, D., \& Putri, D. (2010). Motivasi mahasiswa terhadap aktivitas olahraga pada sore hari di sekitar area taman sutera universitas negeri semarang. Journal of Physical Education And Sport, 10(1), 19-24. https://doi.org/10.1016/j.ejogrb.201 2.06.022

Abidin, A., \& Priambodo, A. (2017). Motivasi partisipasi peserta ukm olahraga di fakultas ilmu keolahragaan universitas negeri surabaya. Jurnal Pendidikan Olahraga Dan Kesehatan, 05(3), 600-606.

Allen, J. B. (2003). Social Motivation in Youth Sport. Journal of Sport and Exercise Psychology, 25(4), 551-567. https://doi.org/10.1123/jsep.25.4.55 1

Ary, D., Jacobs, L. C., Sorensen, C., \& Razavieh, A. (2010). Introduction to Research in Education. Wadsworth, Cengage Learning.

Asnaldi, A., Zulman, \& Madri, M. (2018). Hubungan Motivasi Olahraga Dan Kemampuan Motorik Dengan Hasil Belajar Pendidikan Jasmani Olahraga Dan Kesehatan Siswa Sekolah Dasar Negeri 16 Sintoga Kecamatan Sintuk Toboh Gadang Kabupaten Padang Pariaman. Jurnal MensSana, 3(2), 1627.

https://doi.org/10.24036/jm.v3i2.75

Blegur, J., \& Mae, R. M. (2018). Motivasi berolahraga atlet atletik dan tinju Sport motivation of athletic and boxing athleetes. Jurnal Keolahragaan, 6(1), 29-37. https://doi.org/http://dx.doi.org/10 $.21831 / \mathrm{jk} . v 6 \mathrm{i} 1.16150$

Dimyati. (2018). Psikologi olahraga: metode latihan mental bola basket. UNY Press.

Dimyati. (2019). Psikologi olahraga untuk sepakbokbola. UNY Press.

Fraenkel, J., Wallen, N., \& Hyun, H. (2012). How to design and evaluate research in education (8th ed.). McGraw-Hill Companies, Inc.

Gillet, N., Vallerand, R. J., Amoura, S., \& Baldes, B. (2010). Influence of coaches' autonomy support on athletes' motivation and sport performance: A test of the hierarchical model of intrinsic and extrinsic motivation. Psychology of Sport and Exercise, 11(2), 155-161. https://doi.org/10.1016/j.psychsport .2009.10.004

Ginting, M., Sitepu, A., \& Jubaedi, A. (2018). Motivasi Siswa Terhadap Olahraga Renang Pada Club Renang Jaka Utama Bandar Lampung. Jurnal Pendidikan Jasmani Kesehatan Dan Rekreasi, 6(3), 1-12.

Kilpatrick, M., Hebert, E., \& Bartholomew, J. (2005). College students' motivation for physical activity: Differentiating men's and women's motives for sport participation and exercise. Journal of American College Health, 54(2), 87-94. https://doi.org/10.3200/JACH.54.2. 87-94

Komarudin. (2015). Psikologi olahraga: latihan keterampilan mental dalam olahraga kompetitif. Rosda.

Maksum, A. (2011). Psikologi olahraga: teori dan aplikasi. Unesa University Press.

Mylsidayu, A. (2018). Psikologi olahraga. Bumi Aksara.

Pelletier, L. G., Rocchi, M. A., Vallerand, R. J., Deci, E. L., \& Ryan, R. M. (2013). Validation of the revised sport motivation scale (SMS-II). Psychology of Sport and Exercise, 14(3), 329-341.

https://doi.org/10.1016/j.psychsport .2012.12.002

Pelletier, L. G., Tuson, K. M., Fortier, M. S., Vallerand, R. J., Briére, N. M., \& Blais, M. R. (1995). Toward a New 
Measure of Intrinsic Motivation,

Extrinsic Motivation, and Amotivation in Sports: The Sport Motivation Scale (SMS). Journal of Sport and Exercise Psychology, 17(1), 3553.

https://doi.org/10.1123/jsep.17.1.35

Ryan, R. M., \& Deci, E. L. (2000). Intrinsic and Extrinsic Motivations: Classic Definitions and New Directions. Contemporary Educational Psychology, 25(1), 54-67. https://doi.org/10.1006/ceps.1999.1 020

Santoso, D. (2015). Perbedaan motivasi berpartisipasi dalam olahraga antara suku Jawa, Madura dan Cina. Jurnal Penjaskora, 2(1), 73-83.

Sujari, Shomad, A., \& Santoso, D. A. (2018). Perbedaan Motivasi Berpartisipasi Dalam Olahraga. Jurnal Olahraga Prestasi, 14(1), 24-33.

Tangkudung, J., \& Mylsidayu, A. (2017). Mental Training: aspek-aspek psikologis dalam olahraga. Cakrawala Cendekia.

Utami, Y., \& Kriswanto, E. (2019). Hubungan minat olahraga dan psychological well-being terhadap prokrastinasi peserta didik di sekolah menengah atas. Jurnal Pendidikan Jasmani Indonesia, 15(2), 41-49.

Vallerand, R. J., \& Losier, G. F. (1999). An integrative analysis of intrinsic and extrinsic motivation in sport. Journal of Applied Sport Psychology, 11(1), 142169.

https://doi.org/10.1080/1041320990 8402956

Zulkarnaen. (2010). Hubungan Motivasi Dengan Partisipasi Masyarakat Dalam Melakukan Aktivitas Olahraga Futsal Di Kota Bekasi. Motion, 1(1), 410. 